\title{
Investigation of CTNNB1 gene mutations and expression in hepatocellular carcinoma and cirrhosis in association with hepatitis B virus infection
}

Davod Javanmard ${ }^{1}$, Mohammad Najafi ${ }^{2}$, Mohammad Reza Babaei ${ }^{3}$, Mohammad Hadi Karbalaie Niya ${ }^{4}$, Maryam Esghaei ${ }^{1}$, Mahshid Panahi ${ }^{4}$, Fahimeh Safarnezhad Tameshkel ${ }^{4,5}$, Ahmad Tavakoli',

Seyed Mohammad Jazayeri ${ }^{6,7}$, Hadi Ghaffari ${ }^{1}$, Angila Ataei-Pirkooh' ${ }^{1}$, Seyed Hamidreaz Monavari ${ }^{1 *}$ and Farah Bokharaei-Salim ${ }^{1,8^{*}}$

\begin{abstract}
Hepatitis B virus (HBV), along with Hepatitis C virus chronic infection, represents a major risk factor for hepatocellular carcinoma (HCC) development. However, molecular mechanisms involved in the development of HCC are not yet completely understood. Recent studies have indicated that mutations in CTNNB1 gene encoding for $\beta$-catenin protein lead to aberrant activation of the Wnt/ $\beta$-catenin pathway. The mutations in turn activate several downstream genes, including $c-M y c$, promoting the neoplastic process. The present study evaluated the mutational profile of the CTNNB1 gene and expression levels of CTNNB1 and C-Myc genes in HBV-related HCC, as well as in cirrhotic and control tissues. Mutational analysis of the $\beta$-catenin gene and HBV genotyping were conducted by direct sequencing. Expression of $\beta$-catenin and c-Myc genes was assessed using real-time PCR. Among the HCC cases, $18.1 \%$ showed missense point mutation in exon 3 of CTNNB1, more frequently in codons 32, 33,38 and 45 . The frequency of mutation in the hotspots of exon 3 was significantly higher in non-viral HCCs (29.4\%) rather than HBV-related cases $(12.7 \%, P=0.021)$. The expression of $\beta$-catenin and $c-M y c$ genes was found upregulated in cirrhotic tissues in association with HBV infection. Mutations at both phosphorylation and neighboring sites were associated with increased activity of the Wnt pathway. The results demonstrated that mutated $\beta$-catenin caused activation of the Wnt pathway, but the rate of CTNNB1 gene mutations was not related to HBV infection. HBV factors may deregulate the Wnt pathway by causing epigenetic alterations in the HBV-related HCC.
\end{abstract}

Keywords: HBV, HCC, $\beta$-Catenin, CTNNB1, Mutation

\footnotetext{
* Correspondence: monavari.hr@iums.ac.ir; bokharaei.f@iums.ac.ir

${ }^{1}$ Department of Virology, Iran University of Medical Sciences, Tehran, Iran

Full list of author information is available at the end of the article
} 


\section{Introduction}

Hepatocellular carcinoma (HCC) is the most occurring malignancy of the liver and with 782,000 new cases annually and 600,000 deaths/year globally accounts for at least $75 \%$ of all liver cancer cases [1, 2]. Major risk factors are chronic infections with Hepatitis B Virus (HBV) and Hepatitis $\mathrm{C}$ Virus (HCV), alcohol, aflatoxin and fatty liver diseases; however, $\mathrm{HBV}$ is implicated as the most common etiological agent of $\mathrm{HCC}$ worldwide [2, 3]. The highest incidence of $\mathrm{HCC}$ is seen in Eastern Asian countries followed by the Asian-Pacific region, and these regions have high rates of $\mathrm{HBV}$ and $\mathrm{HCV}$. Hepatic carcinogenesis is a multistep process characterized by multiple genetic alterations whose mechanisms are not fully understood $[1,2]$.

Genetic mutations and aberrant activation of signal transduction pathways play important roles in the development of HCC. It has been confirmed that several signaling pathways are aberrantly activated in $\mathrm{HCC}$ development [4]. Among these, the Wnt/ $\beta$-catenin pathway seems to play a pivotal role in initiating and sustaining HCC development [5].

In the canonical Wnt pathway, $\beta$-catenin is the main effector normally sequestered by the destruction complex [6]. In the absence of Wnt ligands, $\beta$-catenin is phosphorylated by GSK3 $\beta$, and subsequently ubiquitinated and degraded in the proteasome [7]. However, in the presence of ligands (Wnt proteins), Wnts interact with receptors (FZDs) and co-receptor molecules (LRP5/ 6), thereby disassembling the destruction complex [8]. This signal leads to cytoplasmic stabilization of $\beta$ catenin and then nuclear transport of $\beta$-catenin. In the nucleus, $\beta$-catenin triggers activation and transcription of downstream target genes through conjunction with TCF/LEF DNA binding proteins. Next, the consequence is stimulation of target genes involved in the cell proliferation and/or carcinogenesis with their protooncogenic effect. Wnt target genes include $c$-Myc, cyclin D1, CTGF, WISP2 and c-fus, among which upregulation of $c-M y c$ leads to proto-oncogenic effect in liver malignancies [8-10].

Mutations in the $\beta$-catenin gene are in association with the development of several human cancers, including HCC [11-13]. Alterations in phosphorylation targets in the $\mathrm{N}$-terminal domain of $\beta$-catenin prevents the phosphorylation of $\beta$-catenin and subsequent proteasomal degradation. This leads to cytoplasmic accumulation of $\beta$-catenin, which in turn translocates to the nucleus and stimulates the transcription of Wnt target genes involved in apoptosis and proliferation [6].

Genetic alteration in liver malignancies shows diverse patterns in different geographical regions which is most likely linked to risk factors and mutations in human genes $[12,14]$. For example, according to the COSMIC database CTNNB1 mutation rate is higher in Europe and Americas than in Asia [12]. Several investigations have addressed the association of CTNNB1 mutations in HCV-associated HCCs $[12,15,16]$. However, few studies with small sample sizes have assessed CTNNB1 mutations in HBV-related HCCs. Moreover, no data was available regarding this pattern in the Middle East and Iran. Therefore, we analyzed the mutational pattern of CTNNB1 gene in a series of $\mathrm{HBV}$ positive $\mathrm{HCC}$ specimens obtained from a cohort of Iranian patients.

\section{Material and methods}

\section{Patients and samples}

Fifty-four fresh frozen (FF) tissues, comprising cases of $\mathrm{HCC}$, liver cirrhosis (LC) and normal histology tissues, were taken by fine needle biopsies from patients attending hospitals affiliated with Iran University of Medical Sciences. Moreover, formalin fixed paraffin embedded (FFPE) samples $(n=111)$ including $\mathrm{HCC}, \mathrm{LC}$ and non-tumor tissues were also retrospectively analyzed. Overall, 165 samples were examined, including HBV positive $\operatorname{HCC}(n=71)$, non-virus related $\mathrm{HCC}(n=34)$, liver cirrhosis $(n=$ $28)$ and tissues with normal histology $(n=32)$. Demographic and clinical information of the patients are briefly shown in Table 1.

Archived samples were collected from March 2013 and FF samples from May 2017 to April 2019. The FF and FFPE samples were histologically examined by an expert pathologist for confirmation of HCC, LC or normal histology. Informed consent was signed by each patient, and the project was approved by the ethical committee of research at IUMS under declaration of Helsinki (Ethic code: IR.IUMS.FMD.REC 1396.9321540004).

Table 1 Demographic and clinical information of the studied population

\begin{tabular}{lllll}
\hline Characteristics & HBV-HCC & Non-viral HCC & LC & Normal liver \\
\hline Number & 71 & 34 & 28 & 32 \\
Male & $55(77.5)$ & $24(70.6)$ & $15(53.6)$ & $20(62.5)$ \\
Female & $16(22.5)$ & $10(29.4)$ & $13(46.4)$ & $12(37.5)$ \\
Age & & & & \\
$\quad$ Mean & $60.2 \pm 12.4$ & $59.2 \pm 14.2$ & $57.8 \pm 13.6$ & $50.5 \pm 14.5$ \\
$\quad<40$ & $4(5.6)$ & $4(11.8)$ & $4(14.3)$ & $7(21.9)$ \\
$40-50$ & $8(11.3)$ & $3(8.8)$ & $3(10.7)$ & $8(25)$ \\
$51-60$ & $19(26.8)$ & $5(14.7)$ & $11(39.3)$ & $11(34.4)$ \\
$>60$ & $40(56.3)$ & $22(64.7)$ & $10(35.7)$ & $6(18.8)$ \\
HBV+ & $71(100)$ & 0 & $12(42.8)$ & $11(34.4)$ \\
Cirrhosis & $20(28.2)$ & $7(20.6)$ & $28(100)$ & - \\
\hline
\end{tabular}




\section{DNA extraction}

DNA was isolated using tissue DNA extraction kit (NucleoSpin ${ }^{\circ}$ Tissue, Mini kit for DNA from cells and tissue, Macherey-Nagel Co, Germany) according to the kit instructions with the use of $1 \mathrm{mg}$ of liver tissue. For each FFPE sample, 10 cuts with $15 \mu \mathrm{m}$ thickness were first underwent for paraffin removal using xylene and ethanol, and then $1 \mathrm{mg}$ of obtained tissue was forwarded in the above DNA isolation kit. The concentration and purity of isolated DNA were checked by BioPhotometer (NanoDrop 1000 Spectrophotometer, Thermo Fisher Scientific, United States) and running in agarose gel.

\section{RNA extraction and synthesis of CDNA}

Isolation of total RNA from FF samples was performed using a tissue RNA extraction kit (NucleoSpin ${ }^{\circ}$ total RNA, MN, Macherey-Nagel Co, Germany). For each FFPE samples, 10 cuts with $10 \mu \mathrm{m}$ thickness were subjected for paraffin removal. We performed additional processing steps to improve RNA extraction from FFPE as described in the supplementary method. Then, the processed samples were used for RNA extraction with the above-mentioned kit. The purity and concentration of obtained RNA were checked by a BioPhotometer (The ratio of 260/280 was optimized between 1.7-2). The concentration and integrity of RNA were observed on agarose gel (Supplementary Figure 1). For gene expression assays, RNA samples were first treated with DNase I (Yekta Tajhiz Azma, YTA, Iran), and then DNase treated RNAs were applied to synthesize cDNA using random hexamer primers in the procedure of the First Strand cDNA Synthesis Kit (Fermentas, Thermo Fisher Scientific TR Limited, Waltham, Massachusetts, United States).

\section{Identification of mutations in CTNNB1 gene}

Several standard PCR assays were designed to identify $\beta$ catenin mutations. In all PCR assays of this study, necessary care was taken to avoid any carry over contamination. All the primers used in this study were synthesized and purchased from Metabion Company (Metabion international AG, Planegg/Steinkirchen, Germany, Table 2).

A single step PCR was designed to amplify exons 3 to 5 (Table 2). The thermal conditions were as follows: preheat at $95^{\circ} \mathrm{C}$ for $10 \mathrm{~min}$, then 45 cycles of $94{ }^{\circ} \mathrm{C}$ for $15 \mathrm{~s}$, $57^{\circ} \mathrm{C}$ for $15 \mathrm{~s}$, and $72{ }^{\circ} \mathrm{C}$ for $1 \mathrm{~min}$ for amplification a 994 base pair product. Moreover, a nested PCR approach was designed for whole exon 3 of the CTNNB1 gene (Table 2).

\section{Determination of the expression levels of $\beta$-catenin and $c$ - Myc}

To assess the active status of the Wnt pathway, the expression levels of $\beta$-catenin and $c-M y c$ mRNAs were evaluated using the SYBR green based real-time PCR assay. Primers used in this section are given in Table 2 . All the RT - PCR programs were performed on a Rotor Gene 3000 Real-Time PCR Machine using SYBR master 2X (2X SYBR ${ }^{\circ}$ Green Real Time PCR Master Mix, Pars Tous Biotechnology, Mashhad, Iran). Samples were tested in duplicates and mean cycles of threshold $(\mathrm{Ct})$ was used for further analyses. Values were normalized relative to the expression level of two internal housekeeping genes (GAPDH and HMBS) [17]. The $2^{-\Delta \Delta C t}$ formula was used for calculation of relative gene expression. In this way, $\Delta \mathrm{Ct}$ means $\mathrm{Ct}$ of target gene -mean $\mathrm{Ct}$ of GAPDH and HMBS, and $\triangle \Delta C \mathrm{Ct}$ is equal to tumor $\Delta$ Ct- normal sample $\Delta$ Ct [19].

\section{Genotyping of HBV}

HBV infection of all samples was investigated using a conventional PCR test, as previously described [18]. Table 2 presents the sequence of primers used; the nested-PCR amplicon was a $417 \mathrm{bp}$ segment corresponding to the HBsAg coding region subsequently

Table 2 The sequence of primers used for amplification of CTNNB1 gene, HBsAg coding region and gene expression analysis

\begin{tabular}{|c|c|c|c|c|c|}
\hline Gene & $\begin{array}{l}\text { Forward } \\
5^{\prime}-3^{\prime}\end{array}$ & $\begin{array}{l}\text { Revers } \\
5^{\prime}-3^{\prime}\end{array}$ & PCR size & $\mathrm{Ta}_{\mathrm{a}}$ & $\overline{\text { Ref }}$ \\
\hline$\beta$-catenin & CGTGGACAATGGCTACTCAA & CACTCAGAGAAGGAGCTGTGG & 150 & 57 & $\mathrm{~b}$ \\
\hline c-Myc & GGACGACGAGACCTTCATCAA & CCAGCTTCTCTGAGACGAGCTT & 92 & 60 & [10] \\
\hline HMBS & CCCTGCCAGAGAAGAGTGTG & GTGTTGAGGTTTCCCCGAAT & 109 & 57 & b \\
\hline GAPDH & CGACCACTITGTCAAGCTCA & AGGGGTCTACATGGCAACTG & 228 & 58 & [17] \\
\hline HBS1 & GAGTCTAGACTCGTGGTGGACTTC & AAATKGCACTAGTAAACTGAGCCA & 448 & 58 & [18] \\
\hline HBS2 & CGTGGTGGACTTCTCTCA ATTTTC & GCCARGAGAAACGGRCTGAGGCCC & 417 & 60 & [18] \\
\hline CTNNB1 ex3-5 & TAGCTGATTTGATGGAGTTGG & CTCACGATGATGGGAAAGGT & 994 & 57 & b \\
\hline CTNNB1 ex3, outer & TGCTITTCTTGGCTGTCTTTC & CCTAAATGGTAAAAGTGACATTGC & 500 & 55 & b \\
\hline CTNNB1 ex3, inner & TGCTAATACTGTTTCGTATTTATAGC & TTCTGACTTTCAGTAAGGCAATG & 293 & 53 & b \\
\hline
\end{tabular}

${ }^{\mathrm{a}} \mathrm{Ta}$ is the temperature of annealing for each primer set

${ }^{\mathrm{b}}$ These primers were designed in current study 
subjected to direct sequencing for HBV genotyping. The obtained sequence data were aligned with the reference sequence of the accession number GQ183486 for construction of the phylogenetic tree using the MEGA software version 7.

\section{Statistical analysis}

The data were categorized in the SPSS package and compared using chi-square, $\mathrm{x}^{2}$ test or Fisher's exact tests. Values lower than 0.05 were considered as significant. Mann-Whitney and student t-test were used to compare quantitative characters. The Graph Pad Prism software (Version 6) was used for graphical analysis of gene expression data.

\section{Results}

Viral characteristics

All samples were investigated for HBV-DNA, and 56.9\% were found to be positive for HBV; 71/105 (67.6\%) among HCC cases, $12 / 28$ (42.8\%) in the cirrhosis group and 11/32 (34.4\%) among liver samples with normal histology (Table 1). In the HCC group, the HBV S gene was partially sequenced and the nucleotide sequences subjected to phylogenetic analysis (Data are not shown) by using the MEGA software and also Geno2Pheno online tool (https://hbv.geno2pheno.org/). The results showed that all characterized samples belonged to the HBV subgenotype D1.

\section{Frequency of mutations in CTNNB1 gene}

Exon 3 and exons 3-5 were amplified using a pfu Taq-DNA polymerase (Yekta Tajhiz Azma, YTA, Iran) (Supplementary Fig. 2), and subjected to sequencing (Bioneer, South Korea). In exon 4, two point mutations (Q85H and D145E) were found only in nonviral HCC (Supplementary Fig. 3). In exon 5, there were two point mutations (Q203H and E209Q); no mutation was identified in both normal and LC group.

Overall, 19/105 of HCC samples (18.1\%) had at least one non-synonymous mutation in the hotspot region of $\beta$-catenin (Table 3, and Fig. 1). Known mutations found in exon 3 were: D32V/G, S33C, H36Q, S37C, G38V/S/R, A39V, T41P, T42A, P44R and S45P. The majority of mutations was observed in codons 32 (n: 3), 38 (n: 3) and 45 (n: 3), in which serine was the most affected amino acid (Fig. 2). No deletion or insertion was identified in the studied regions. However, there were some other unknown missense and nonsense mutations listed in the supplementary table. Among LC and normal tissues, there was no mutation in exon 3 of the $\beta$-catenin gene.
Table 3 CTNNB1 mutation in HCC cases according to demographic and pathological characteristics

\begin{tabular}{lll}
\hline Characteristics & CTNN mutation N (\%) & P \\
\hline Male & $14(17.7)$ & 0.575 \\
Female & $5(19.2)$ & \\
Age & & $0.034^{\mathrm{a}}$ \\
$40>$ & $1(12.5)$ & \\
$40-50$ & $1(9.1)$ & \\
$51-60$ & $4(16.6)$ & $0.097^{\mathrm{b}}$ \\
$>60$ & $13(21)$ & \\
Differentiation & & \\
$\quad$ Well & $9(28.1)$ & \\
$\quad$ Moderate & $5(16.7)$ & \\
Poorly & $4(15.4)$ & 0.423 \\
Un-known & $1(5.9)$ & \\
LC-HCC & & \\
Yes & $4(14.8)$ & \\
No & $15(19.2)$ &
\end{tabular}

${ }^{\mathrm{a}}$ The frequency of mutations was significantly increased toward aging, ${ }^{\mathrm{b}}$ The rate of mutations in well differentiated tumors was higher than others

\section{Mutations of CTNNB1 in association to HBV infection}

The frequency of mutations in the hotspots of exon 3 was significantly higher in non-viral HCC rather than HBV-related ones $(P=0.021)$. Overall, 9/71 (12.7\%) of HBV-HCCs, and 10/34 (29.4\%) in nonviral HCCs had a mutation in the hotspot region of $\beta$-catenin. Furthermore, the pattern of mutations was also different between HBV-HCC and non-viral HCC (Fig. 2). A mutation in codon 33 (S33C) was the most prevalent mutation found in three HBV-HCC samples. Some mutations were observed more prevalently in HBV-HCCs; S33C (n: 3), H36Q (n: 1), S37C (n: 1) and A39V (n: 1); however, other mutations were seen in both groups (S33C, P44R and S45P). Tissues with non-viral HCC had a higher frequency of mutation in codon 32, 38 and 45 rather than HBV-related ones (5.8\% vs $1.4 \%$ for each mutation). Moreover, the type of amino acid change was also different in these positions: $G$ vs $Y$ in 32 and $R$ vs $V$ in 38 (Fig. 2). The frequency of mutation in codon 44 was equal, and the type of change was also similar in tumors with both etiologies (P44R). Nevertheless, T41I and T42A mutations were identified only in non-viral tumors.

\section{Determination of $\beta$-catenin expression level}

The results of real-time PCR showed that the expression level of $\beta$-catenin was significantly higher among the tumor samples than in the normal group (Fig. 3, Fig. 4). Elevated levels of $\beta$-catenin and $c$ Myc expression were observed also in cirrhotic 


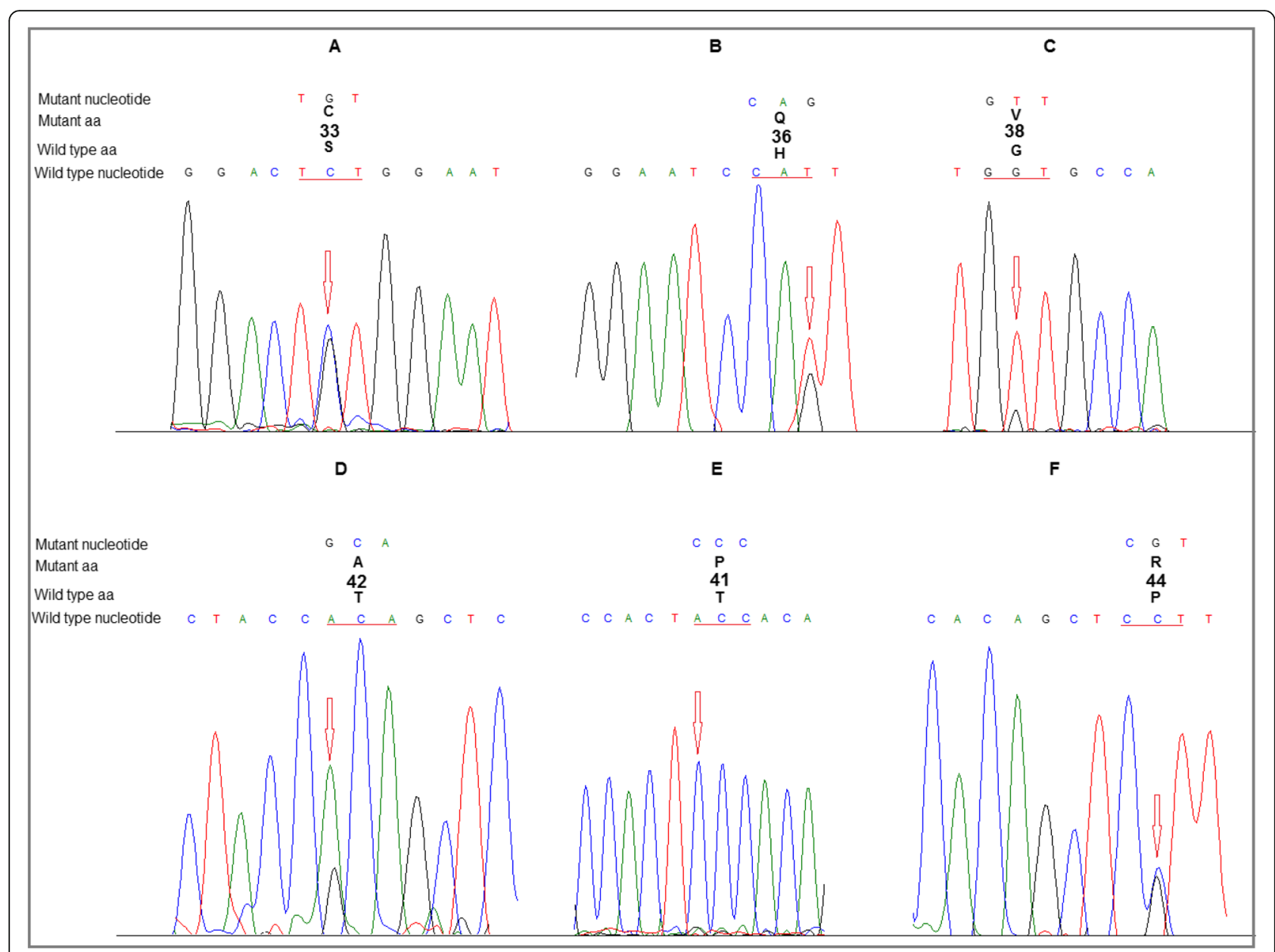

Fig. 1 Examples of representative sequence chromatograms of the identified mutations in the hotspot region of $\beta$-catenin gene. A: S33C, B: H36Q, C: G38V, D: T42A, E: T41P, F: P44R

samples (Fig. 3, Fig. 4). Higher levels of $\beta$-catenin and $c-M y c$ were found in the HBV-LC group than non-viral-LC group; however, the expression level of $c-M y c$ was not statistically different between HBVHCC and non-viral HCC groups (Fig. 3).
Determination of the expression level of $\beta$-catenin in association to mutations

Next, we aimed to determine whether the mutation phenotypes identified in HCC tumors were associated with the activation of the Wnt pathway. Considering that $c$ -

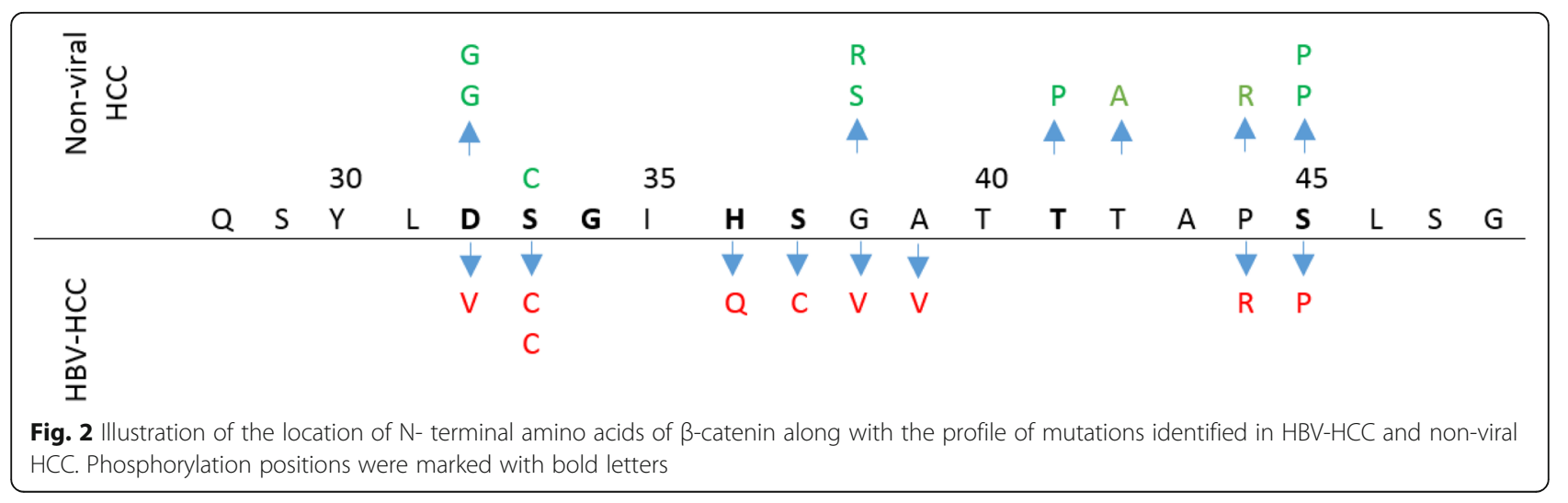




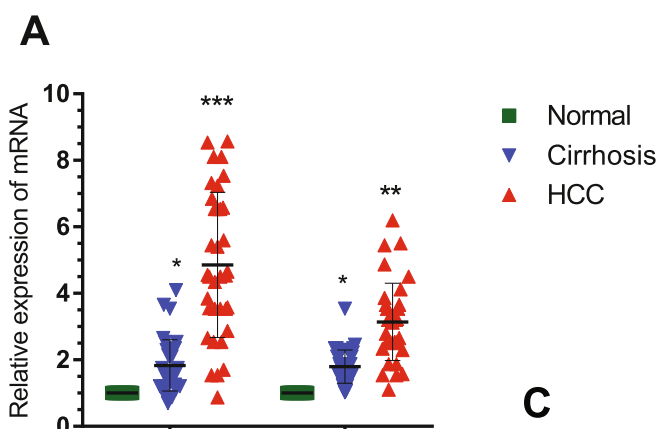

B
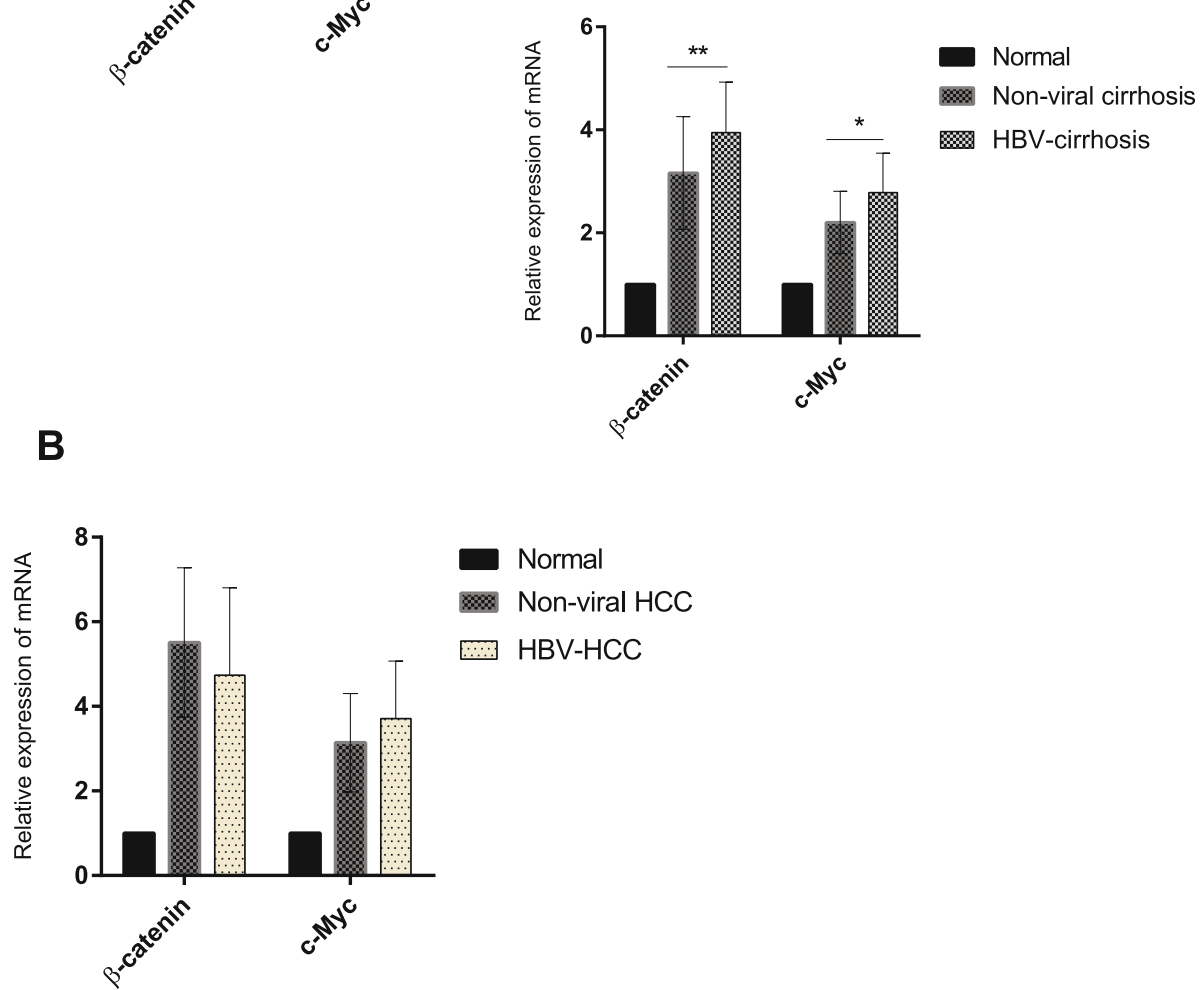

Fig. 3 The results of real-time PCR for $\beta$-catenin and c-Myc were analyzed in normalization to the mean expression level of GAPDH and HMBS and in adjustment to the control group. The result showed that the expression of $\beta$-catenin and c-Myc was significantly upregulated among cases with LC and HCC (a). The expression among HBV-HCC and non-viral HCC was not statistically different (b). The expression of these genes showed elevated levels among HBV-LC (c). *: $p<0.05,{ }^{* *}: p<0.005,{ }^{* * *}: p<0.0005,{ }^{* * *}: p<0.00005$

Myc is one of the target genes of this pathway [20], Wnt activation was assessed by analyzing $c-M y c$ expression levels following normalization to the GAPDH gene.

Tumor samples harboring at least one missense mutation in the hotspot region of $\beta$-catenin revealed significant higher levels of $c-M y c$ compared to wild type cases (Fig. 5). Among different mutation sites identified in this study, mutations at positions 32 and 45 were related to higher levels of $c-M y c$. Moreover, it appeared that mutation in both phosphorylation sites (32, 33, 36, 37, 41 and 45) as well neighboring sites within the hotspot region (39 and 44) could result in upregulation of $c-M y c$ (Fig. 5). Among cases with mutation in exons 4 and 5 , no significant difference was observed in term of gene expression (Fig. 5).

\section{Discussion}

Molecular mechanisms involved in the development of HCC are not yet completely understood. This is partly owing to different etiologies of HCC as well as genetic heterogeneity of the patients. Overexpression and activation of $\beta$-catenin are now regarded as a frequent event in the development of HCC, which may be caused by mutations in the CTNNB1 gene as well as some other epigenetic factors. Hence, we examined the mutation status in exons $3-5$ of the CTNNB1 gene and expression level of $\beta$-catenin gene in association with $\mathrm{HBV}$ infection.

Among HCC cases, we found two non-synonymous nucleotide changes in exon 4 and two in exon 5 of 


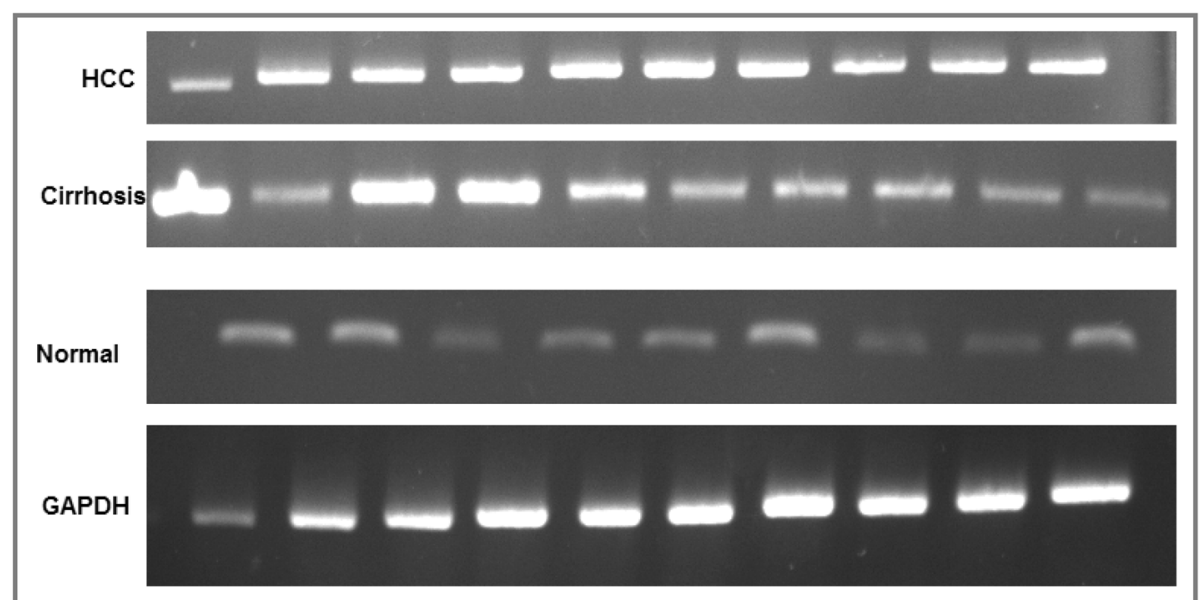

Fig. 4 RT-PCR product of $\beta$-catenin was resolved in agarose gel, and the intensity of the bands were semi-quantified with GelCount ${ }^{\text {TM }}$ software. Elevated expression of $\beta$-catenin in HCC and LC groups was observed in comparison to controls. All the lanes represent the samples tested

CTNNB1 gene. These exons correspond to the $\mathrm{N}$ terminus domain of $\beta$-catenin that can be a phosphorylation site for GSK3 $\beta$ or casein kinase-1, and/or a binding site for alpha-catenin in a complex with nuclear factors (TCF/ LEF) [21]. However, mutated cases in exons 4 and 5 did not show elevated levels of $\beta$-catenin compared to wild types that may be due to the low number of mutated samples. Although most previous studies were focused more on exon 3 among HCC patients, the present study found some unknown mutations in exons 4 and 5 for the first time. However, previous studies reported mutations in exons 4 and 5 in different cancers of unknown primary and some cancer cell lines [11, 22-24].

Totally, $18.1 \%$ of HCC cases were mutated in the $\beta$ catenin-exon 3; this is the first report from the Middle East and Iran. This rate was significantly higher in nonviral $\mathrm{HCC}$ rather than $\mathrm{HBV}$-related $\mathrm{HCC}(29.4 \%$ vs $12.7 \%)$. Similar findings were reported in most of previous studies and the rate of mutation in HBV-HCC ranged from 8 to $19 \%$ [15, 25-32], and even higher as 44.1\% [9]. Otherwise, this figure among HCV-HCC and/ or non-viral HCC tumors was previously reported in high levels from 28 to 50\% [33-36], being much higher than our study. Our results appear to be moderately lower than reports from France [37], Japan [16, 38], Italy [15] and Europe [28]; however, it should be noted that $\mathrm{HCV}$ is more prevalent in those regions. Additionally, $\mathrm{HBV}$ is the leading cause of HCC in Iran and the Middle East [39]. Accordingly, it appears that there is a geographical pattern of CTNNB1 mutation in coordination with the epidemiologic profile of $\mathrm{HBV} / \mathrm{HCV}$ as well as other risk factors such as aflatoxins and alcohol, being higher in more developed countries rather than developing and under-developed countries [12, 40].
Furthermore, some studies did not find any CTNNB1 mutation in HBV-HCC tumors [13] or even among HCC cases with other etiologies among black Africans $[41,42]$. The reason for these intense negative results is not yet fully understood. However, it is well known that genetic origin and heterogenecity affect the mutation rates. Studies have indicated that mutation pattern and frequencies can be variable according to heterogeneity in etiology, host genetic and geographical regions [15]. Moreover, among the known driver HCC genes, there is an obvious different geographical pattern of mutation for TP53 and RB1 genes that are related to ancestry genetic [40].

Moreover, we demonstrated that HBV-HCCs had a unique profile of CTNNB1 mutation pattern; S33C, H36Q, S37C and A39V were observed mostly in HBV$\mathrm{HCC}$, some of them are also reported in previous studies $[29,43]$. Of these, positions at 33 and 37 are the target phosphorylation sites for GSK3 $\beta$ [21], and H36 increases the activity of Wnt target genes [7].

Mutations of $\beta$-catenin have already been found to be associated with nuclear accumulation of $\beta$-catenin, leading to transactivation and overexpression of Wnt target genes including $c-M y c$, cyclin D1, CTGF, and WISP2 [9, 20, 44]. Therefore, we assessed the activation status of the Wnt pathway according to the expression level of $c$ Myc. Mutations at positions 32 and 45 were mostly related to elevated levels of $c-M y c$. However, mutations in both phosphorylation sites and other sites within the hotspot region result in upregulation of $c-M y c$. This finding is in line with previous studies reporting an elevated level of $c-M y c$ among mutated HCC tumors compared to normal or wild type samples [8, 9, 41]. Functional effects of these mutations were not 


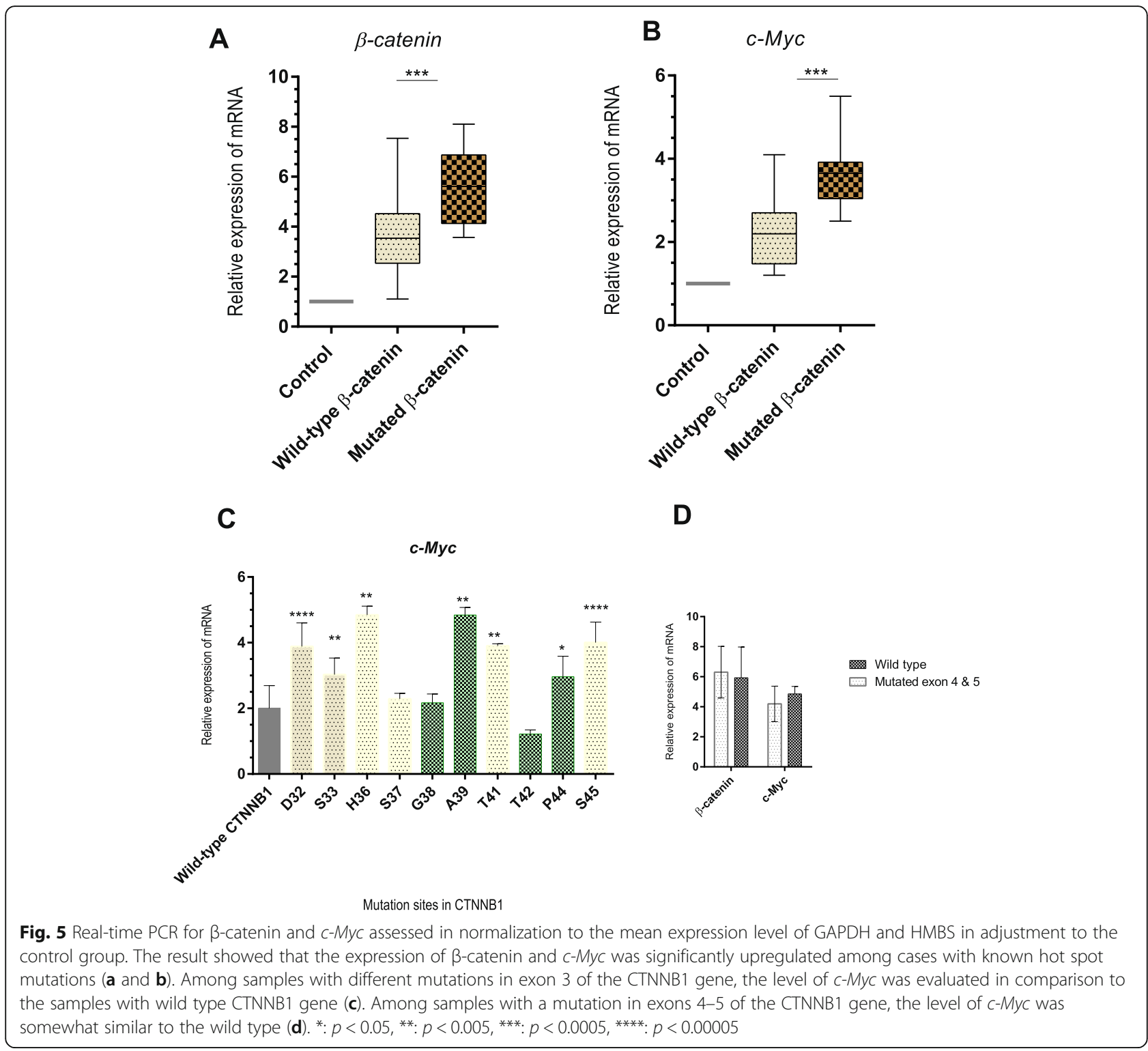

previously investigated among clinical samples. Mutations in this region lead to interference in the phosphorylation of $\beta$-catenin by the destruction complex (Axin, APC, CK1, and GSK3- $\beta$ ) and prevent subsequent proteasomal degradation of $\beta$-catenin, resulting in cytoplasmic accumulation and translocation of $\beta$-catenin to the nucleus and activation of the pathway by contributing with $\mathrm{Tcf} /$ Lef transcription factors [20].

Mutations of $\beta$-catenin lead to steady activation of the Wnt pathway, which may occur early in some tumors [21]. Moreover, higher levels of $\beta$-catenin may lead to the release of this protein from the Axin-APC scaffold complex [45] and translocation of free molecules to the nucleus. Thus, elevated levels of $\beta$-catenin may lead to nuclear accumulation of $\beta$-catenin and activation of the pathway. The current study results showed the overexpression of $\beta$-catenin among tumor samples as well as CTNNB1 mutated cases, being accompanied by overexpression of $c-M y c$. Some previous studies also demonstrated transcriptional dysregulation and overexpression of CTNNB1 [9, 46]. This suggests that deregulation of the Wnt pathway begins at the transcription level, as well as previous findings that $\beta$-catenin expression is in accordance with the protein and mRNA level [9].

There was an elevated levels of $\beta$-catenin and $c-M y c$ expression in LC group that was associated to HBV infection. This finding was previously described with decreased level of serum $\beta$-catenin from chronic hepatitis B, HBV-LC to HBV-HCC [47]. However, no mutation was found in CTNNB1 among the LC group. This finding suggest that $\beta$-catenin mutations and other liver 
injuries such as cirrhosis are not necessarily cooperative risk factors of $\mathrm{HCC}$, and so they may independently contribute to the development of HCC [48].

The most important limitation of this study was the lack of functional tests to assess the effect of viral factors on the Wnt pathway, as well as in-vivo and in-vitro based experiments for exact elucidation of HBV-related up- or downregulation in gene expression.

In conclusion, a significant number of $\beta$-catenin mutations were identified in this study that were related to the overexpression of $\beta$-catenin. Overexpression of this gene was correlated with higher expression of $c-M y c$ as one of Wnt pathway target genes. Overexpression of $\beta$ catenin and $c-M y c$ in $\mathrm{LC}$ appeared to be an earlier event before development of HBV-HCC. HBV infection was not involved in the occurrence of mutations in the $\beta$ catenin gene; therefore, dysregulation of the Wnt pathway may be mediated by the effect of viral factors on other role players in the pathway. We found some unknown mutations in exons 4 and 5 of $\beta$-catenin that need further investigations in larger sample sizes to evaluate of the exact effect.

\section{Supplementary information}

Supplementary information accompanies this paper at https://doi.org/10. 1186/s13027-020-00297-5.

Additional file 1: Figure S1. The electrophoresis of RNAs on agarose gel. Figure S2. PCR products of $\beta$-catenin exons $3-5$ on agarose gel. Figure S3. Unknown point mutations observed in exons $3-5$ in the $\beta$ catenin among HCC samples. Table S1. List of mutations observed in this study.

\section{Abbreviations}

HCC: hepatocellular carcinoma; HBV: hepatitis B virus; LC: liver cirrhosis; Wnt: Wingless-related integration site (Wingless family protiens); c-Myc: cellMyelocytomatosis; GSK3ß: Glycogen synthase kinase 3 beta; FZD: frizzled class receptors; LRP: Low-density lipoprotein receptor-related protein; Axin: Protein Phosphatase, Component of the beta-catenin destruction complex required for regulating CTNNB1 levels; APC: Adenomatous polyposis coli; TP53: Tumor protein p53; CTNNB1: Catenin (Cadherin-Associated Protein), Beta 1, 88 kDa; GAPDH: Glyceraldehyde-3-Phosphate Dehydrogenase; HMBS: Hydroxymethylbilane Synthase; RB1: Retinoblastomaassociated protein; CTGF: CCN2, connective tissue growth factor; WISP: (CCN5) WNT1 inducible signaling pathway protein subfamily; CK1: Casein kinase 1 family

\section{Acknowledgments}

This work was fully supported by Iran University of Medical Sciences (IUMS). The results of the current study were part of a Ph.D thesis by the first author (Grant number: 9321540004). We would like to express our sincere gratitude to the Dr. Seyed Jalal Kiani for his helpful advices.

\section{Authors' contributions}

Concept of idea, design and experiments: D Javanmard, SH Monavari, F Bokharaei-Salim and M Najafi; Methodology and technical support: D Javanmard, M Najafi, MH Karbalaie Niya, F Bokharaei-Salim, M Esghaei and SM Jazayeri; Sampling and patients data: D Javanmard, F Safarnezhad Tameshkel, M Panahi, MR Babaei, A Ataei-Pirkooh and SM Jazayeri; Draft of manuscript and critical revision: D Javanmard, A Tavakoli and $\mathrm{H}$ ghaffari. All authors read and approved the final manuscript.

\section{Funding}

This study was funded and supported by the IUMS

\section{Availability of data and materials}

Data and complementary material are available and was uploaded in supplementary file.

\section{Ethics approval and consent to participate}

The project was approved in the ethical committee of research at IUMS under declaration of Helsinki (Ethic code: IR.IUMS.FMD.REC 1396.9321540004).

\section{Consent for publication}

There is consent for publication in the deputy of research at Iran University of Medical Sciences (IUMS).

\section{Competing interests}

All the authors have stated to have no conflict of interest for declaration.

\section{Author details}

${ }^{1}$ Department of Virology, Iran University of Medical Sciences, Tehran, Iran. ${ }^{2}$ Department of Biochemistry, School of Medical Sciences, Iran University of Medical Sciences, Tehran, Iran. ${ }^{3}$ Department of Interventional Radiology, Firouzgar Hospital, Iran University of Medical Sciences, Tehran, Iran. ${ }^{4}$ Gastrointestinal and Liver Diseases Research Center, Iran University of Medical Sciences, Tehran, Iran. ${ }^{5}$ Student Research Committee, Iran University of Medical Sciences, Tehran, IR, Iran. ${ }^{6}$ Department of Virology, Tehran University of Medical Science, Tehran, Iran. ${ }^{7}$ Research Center for Clinical Virology, Tehran University of Medical Sciences, Tehran, Iran. ${ }^{8} \mathrm{HIV}$ Laboratory of National Center, Deputy of Health, Iran University of Medical Sciences, Tehran, Iran

Received: 29 October 2019 Accepted: 4 May 2020

Published online: 03 June 2020

\section{References}

1. Ozakyol A. Global epidemiology of hepatocellular carcinoma (HCC epidemiology). Journal of Gastrointestinal Cancer. 2017;48(3):238-40.

2. Sayiner M, Golabi P, Younossi ZM. Disease burden of hepatocellular carcinoma: a global perspective. Dig Dis Sci. 2019;64(4):910-7.

3. Rawla, P., et al., Update in global trends and aetiology of hepatocellular carcinoma. Contemporary oncology (Poznan, Poland), 2018. 22(3): p. 141150.

4. Khalaf AM, et al. Role of Wnt/ $\beta$-catenin signaling in hepatocellular carcinoma, pathogenesis, and clinical significance. Journal of hepatocellular carcinoma. 2018;5:61-73

5. Li Q-M, et al. Influence of polymorphisms in the Wnt/B-catenin pathway genes on hepatocellular carcinoma risk in a Chinese Han population. Medicine. 2017:96(12):e6127.

6. MacDonald BT, Tamai K, He X. Wnt/B-catenin signaling: components, mechanisms, and diseases. Dev Cell. 2009:17(1):9-26.

7. Austinat $\mathrm{M}$, et al. Correlation between $\beta$-catenin mutations and expression of Wnt-signaling target genes in hepatocellular carcinoma. Mol Cancer. 2008;7(1):21

8. Kim M, et al. Functional interaction between Wnt3 and Frizzled-7 leads to activation of the $\mathrm{Wnt} / \beta$-catenin signaling pathway in hepatocellular carcinoma cells. J Hepatol. 2008;48(5):780-91.

9. Cui J, et al. Wnt signaling in hepatocellular carcinoma: analysis of mutation and expression of beta-catenin, T-cell factor-4 and glycogen synthase kinase 3-beta genes. J Gastroenterol Hepatol. 2003:18(3):280-7.

10. Hsieh A, et al. Hepatitis B viral $X$ protein interacts with tumor suppressor adenomatous polyposis coli to activate $W n t / \beta$-catenin signaling. Cancer Lett. 2011;300(2):162-72.

11. Chen S-P, et al. $\beta$-Catenin and K-ras mutations and RASSF1A promoter methylation in Taiwanese colorectal cancer patients. Genetic testing and molecular biomarkers. 2012;16(11):1277-81.

12. Tornesello ML, et al. Mutations in TP53, CTNNB1 and PIK3CA genes in hepatocellular carcinoma associated with hepatitis $B$ and hepatitis $C$ virus infections. Genomics. 2013;102(2):74-83.

13. Saitta $C$, et al. Evaluation of CTNNB1 and TP53 variability in patients with hepatocellular carcinoma and occult hepatitis B virus infection. Cancer genetics. 2015;208(10):513-6. 
14. Unsal H, et al. Genetic heterogeneity of hepatocellular carcinoma. Proc Natl Acad Sci. 1994:91(2):822-6.

15. Pezzuto $F$, et al. Tumor specific mutations in TERT promoter and CTNNB1 gene in hepatitis B and hepatitis C related hepatocellular carcinoma. Oncotarget. 2016;7(34):54253.

16. Huang $\mathrm{H}$, et al. $\beta$-Catenin mutations are frequent in human hepatocellular carcinomas associated with hepatitis C virus infection. Am J Pathol. 1999; 155(6):1795-801.

17. Bahrami F, et al. Purine-metabolizing ectoenzymes control IL-8 production in human colon HT-29 cells. Mediat Inflamm. 2014;2014.

18. Ziaee $M$, et al. Genotyping and mutation pattern in the overlapping MHR region of HBV isolates in Southern Khorasan, Eastern Iran. Hepat Mon. 2016; 16(10).

19. Livak, K.J. and T.D. Schmittgen, Analysis of relative gene expression data using real-time quantitative PCR and the 2- $\Delta \Delta C T$ method. methods, 2001. 25(4): p. 402-408.

20. Daud $M$, et al. Modulation of Wnt signaling pathway by hepatitis B virus. Arch Virol. 2017;162(10):2937-47.

21. Gao C, et al. Exon 3 mutations of CTNNB1 drive tumorigenesis: a review. Oncotarget. 2018;9(4):5492.

22. Pentheroudakis $G$, et al. Mutational profiling of the RAS, PI3K, MET and bcatenin pathways in cancer of unknown primary: a retrospective study of the Hellenic cooperative oncology group. Clinical \& experimental metastasis. 2014;31(7):761-9.

23. Ueda $M$, et al. Mutations of the $\beta$-and $\gamma$-catenin genes are uncommon in human lung, breast, kidney, cervical and ovarian carcinomas. Br J Cancer. 2001;85(1):64-8.

24. Ilyas $M$, et al. $\beta$-Catenin mutations in cell lines established from human colorectal cancers. Proc Natl Acad Sci. 1997;94(19):10330-4.

25. Ding $S-L$, et al. Integrative analysis of aberrant Wnt signaling in hepatitis $B$ virus-related hepatocellular carcinoma. World J Gastroenterol: WJG. 2015; 21(20):6317.

26. Li M, et al. Inactivating mutations of the chromatin remodeling gene ARID2 in hepatocellular carcinoma. Nat Genet. 2011;43(9):828.

27. Laurent-Puig P, et al. Genetic alterations associated with hepatocellular carcinomas define distinct pathways of hepatocarcinogenesis. Gastroenterology. 2001;120(7):1763-73.

28. Rebouissou S, et al. Genotype-phenotype correlation of CTNNB1 mutations reveals different $B$-catenin activity associated with liver tumor progression. Hepatology. 2016;64(6):2047-61.

29. Hsu H-C, et al. $\beta$-Catenin mutations are associated with a subset of lowstage hepatocellular carcinoma negative for hepatitis B virus and with favorable prognosis. Am J Pathol. 2000;157(3):763-70.

30. Park JY, et al. Mutations of $\beta$-catenin and AXIN I genes are a late event in human hepatocellular carcinogenesis. Liver Int. 2005;25(1):70-6.

31. Lee SE, et al. Frequent somatic TERT promoter mutations and CTNNB mutations in hepatocellular carcinoma. Oncotarget. 2016;7(43):69267.

32. Edamoto $Y$, et al. Alterations of RB1, p53 and Wnt pathways in hepatocellular carcinomas associated with hepatitis $C$, hepatitis B and alcoholic liver cirrhosis. Int J Cancer. 2003;106(3):334-41.

33. An P, et al. Host and viral genetic variation in HBV-related hepatocellula carcinoma. Front Genet. 2018;9:261.

34. Amaddeo $\mathrm{G}$, et al. Integration of tumour and viral genomic characterisations in HBV-related hepatocellular carcinomas. Gut. 2015;64(5):820-9.

35. Cieply $B$, et al. Unique phenotype of hepatocellular cancers with exon-3 mutations in beta-catenin gene. Hepatology. 2009;49(3):821-31.

36. Taniguchi $\mathrm{K}$, et al. Genetic and epigenetic characteristics of human multiple hepatocellular carcinoma. BMC Cancer. 2010;10(1):530.

37. de La Coste $A$, et al. Somatic mutations of the $\beta$-catenin gene are frequent in mouse and human hepatocellular carcinomas. Proc Natl Acad Sci. 1998; 95(15):8847-51.

38. Kawai-Kitahata F, et al. Comprehensive analyses of mutations and hepatitis $B$ virus integration in hepatocellular carcinoma with clinicopathological features. J Gastroenterol. 2016:51(5):473-86.

39. Alavian, S.M., Hepatocellular Carcinoma is an Emerging Issue Now in Iran. 2018, Kowsar.

40. Yao S, et al. Differences in somatic mutation landscape of hepatocellular carcinoma in Asian American and European American populations. Oncotarget. 2016;7(26):40491.

41. Elmileik H, Paterson AC, Kew MC. $\beta$-Catenin mutations and expression, 249serine $\mathrm{p} 53$ tumor suppressor gene mutation, and hepatitis B virus infection in southern African blacks with hepatocellular carcinoma. J Surg Oncol. 2005:91(4):258-63.

42. Herath NI, et al. Cadherin/catenin complex appears to be intact in hepatocellular carcinomas from Australia and South Africa. J Gastroenterol Hepatol. 2004;19(6):676-82.

43. Ding $X$, et al. Transcriptomic characterization of hepatocellular carcinoma with CTNNB1 mutation. PLoS One. 2014;9(5).

44. Chen $Z$, et al. $\mathrm{HB} \times$ mutations promote hepatoma cell migration through the Wnt/ $\beta$-catenin signaling pathway. Cancer Sci. 2016;107(10):1380-9.

45. Dajani $R$, et al. Structural basis for recruitment of glycogen synthase kinase $3 \beta$ to the axin-APC scaffold complex. EMBO J. 2003:22(3):494-501.

46. Haines $\mathrm{K}$, et al. Characterization of pediatric hepatocellular carcinoma reveals genomic heterogeneity and diverse signaling pathway activation. Pediatr Blood Cancer. 2019;66(7):e27745.

47. Duan $L$, et al. Identification of serum $\beta$-catenin as a biomarker in patients with HBV-related liver diseases. J Transl Med. 2018;16(1):1-11.

48. Monga SP. $\beta$-Catenin signaling and roles in liver homeostasis, injury, and tumorigenesis. Gastroenterology. 2015;148(7):1294-310.

\section{Publisher's Note}

Springer Nature remains neutral with regard to jurisdictional claims in published maps and institutional affiliations.
Ready to submit your research? Choose BMC and benefit from:

- fast, convenient online submission

- thorough peer review by experienced researchers in your field

- rapid publication on acceptance

- support for research data, including large and complex data types

- gold Open Access which fosters wider collaboration and increased citations

- maximum visibility for your research: over $100 \mathrm{M}$ website views per year

At $\mathrm{BMC}$, research is always in progress.

Learn more biomedcentral.com/submissions 